Derecho y Realidad

Vol.13 - Núm. 26 • Julio-Diciembre de 2015

Págs. 99-120 • ISSN:1692-3936

\title{
Especulación sobre los riesgos de negociar la paz con base en reglas de juego culturalmente violentas. El caso de los valores religiosos católicos de Colombia*
}

Some speculation about the risks of negotiate the political peace process based on violent cultural game rules. The case of Colombian catholic religious values

Bernardo Congote Ochoa**

\section{Resumen}

El artículo especula acerca de la incidencia que pueden tener los valores culturales católicos operando como reglas de juego del proceso negociador de paz en Colombia. Su hipótesis sugiere que, dado el perfil político violento de los valores católicos, estas reglas conspirarían contra la seguridad de las negociaciones $y$, por ende, pondría en riesgo la implementación sostenible

Fecha de aceptación: 2 de septiembre de 2015

Concepto de recepción: 9 de octubre de 2014

Fecha de aprobación: 25 de febrero de 2015

* El artículo desarrolla los argumentos expuestos por el autor en su calidad de ponente invitado al IV Congreso Internacional de Derechos Humanos, organizado por la Facultad de Derecho y Ciencias Sociales de la Universidad Pedagógica y Tecnológica de Colombia. La ponencia se llevó a cabo el martes 27 de octubre del año 2015 en la sede central de la Universidad en la ciudad de Tunja, Boyacá, Colombia.

** Investigador Junior (Colciencias, 2015-2016). Profesor de medio tiempo, Universidad Antonio Nariño, Investigador Grupo SErvipúblicos, Universidad Distrital FJC. Profesor de hora cátedra, Universidad Distrital FJC. bernardo.congote@uan.edu.co 
de sus acuerdos. El artículo ofrece algunas señales de la genealogía cultural católica de Colombia y su relación con su estado de violencia política permanente. Con base en estas señales, aplica herramientas de teoría de juegos para evaluar el proceso negociador de paz de La Habana, concluyendo que mientras los negociadores de la paz no sustituyan el actual juego de suma cero con solución Pierde-Pierde, basado en las reglas culturales religiosas católicas, por otro del Seguro, estructuralmente civilista y demócrata de tipo Gana-Gana, el proceso negociador continuará en riesgo tanto como la implementación sostenible de sus acuerdos.

\section{Palabras clave}

Catolicismo, cultura, juegos, paz, valores, violencia.

\section{Abstract}

The article speculates about the Colombian catholic cultural values incidence over the actual peace process. Our hypothesis suggests that the violent political profile of Catholic values acting as the game rules of the peace process conspires against the negotiations accuracy as well as against the agreements implementation sustainability. The article describes some signals about Colombian catholic culture genealogy and its relationships whit the historically persistent violence status of this country. Based upon these assumptions, it applies some Game Theory tools to evaluate the actual peace process negotiation between Colombian government and FARC insurgency in which the rules are influenced by the Catholic warrior values. And it concludes that while peace negotiators do not substitute the actual zero sum game linked to a Prisoners Dilemma's game with Lost-Lost solution, instead of playing a Win-Win solution game linked to Insurance mechanism, the peace process and the post implementation of its agreements will continue to be highly risky as well as unsustainable.

\section{Keywords}

Catholics, culture, games, peace, values, violence. 


\section{Sumario}

1. Algunos valores católicos y su conexión con la expresión violenta de lo político

2. Manifestaciones guerreras de la catolicidad 3 La máquina de guerra catolizada y el proceso de paz 4 Estudio del caso (2012-2014)

3. Conclusiones.

\section{Método}

Filosófico deductivo.

\section{Metodología}

El artículo es del tipo descriptivo explicativo. Sus argumentos provienen del proceso investigativo que condujo a optar por la tesis de maestría reseñada en Congote, 2004. Sus aspectos descriptivos, son de orden históricos y políticos. Los explicativos, se basan en la aplicación de la Teoría de Juegos para analizar y concluir preliminarmente, en relación con el desarrollo y perspectivas del proceso de negociación de un acuerdo de paz, iniciado en 2012 entre el Gobierno de Colombia y la insurgencia denominada Fuerzas Armadas Revolucionarias de Colombia (FARC). 


\section{Introducción}

\section{Algunos valores católicos y su conexión con la expresión violenta de lo político}

No se suele considerar políticamente correcto emplear variables culturales para investigar en ciencia política. Ello explica que esta disciplina padezca de cierto aculturalismo metodológico en la prueba de sus hipótesis (Ross, 1999; Geertz, 1973). El artículo propone, al contrario, que los valores culturales religiosos sí permiten entender la sociedad, dado que "Las prácticas religiosas son potencialmente capaces de afirmar y revitalizar identidades, renombrar territorios, [...] construir proyectos de vida [...] y expresar conflictos sociales, resistencias, tensiones y negociaciones entre lo local, lo regional y lo global, entre [...] lo 'pagano' y la oficialidad católica [...]" (Ferro, 1999, p. 6) $)^{1 / 2}$

Y también considera que:

En la experimentación colonial hispánica, [...] la lógica cristiana[...] cristaliza primero en el elemento embrionario del Estado colonial y, posteriormente, en el Estado republicano [mediante...] una metodología [...] que usa la creencia como un sistema de conocimiento, con lo cual la Iglesia logra inventar una cultura, cimentando sociedades [...] integradas al sistema de creencias católico [...] Por esta razón, se la considera [...] centro de[...] problematización de los acontecimientos coloniales y post coloniales [a pesar de lo cual] su rol modelador [...] de una cultura ha sido débilmente considerado" (Zuleta, 2013, pp. 9-37. 97-152. Negrilla del artículo).

\section{El autodesprecio}

La propuesta jesuita sobre el autodesprecio, paradigmática de lo católico, apunta a la desfiguración de sí mismo hasta el punto de convertirlo en virtud, reafirmando que "[...] el cadáver [sea] la más perfecta afirmación del espíritu" (Bataille, 1981, pp. 43, 44). Inocencio III Papa ratificó el autodesprecio como valor católico, presentando al cuerpo humano como "[...] concepción impura, alimentación nauseabunda en el seno materno, mala cualidad de la materia de la que el hombre se desarrolla, hedor asqueroso, secreción de esputos, orina y excrementos" (De Loyola, 1947, pp. 145-174. Hayek, 1996 (1), p. 30. Nietzsche, 1994, p. 77).

\footnotetext{
Ver también: Barabas, 1991a, p.7. 1991b, pp. 19-21. Schwimmer, 1982, p.9.

2 A no ser que se evidencie lo contrario, las notas entre corchetes dentro de las citas son responsabilidad del artículo.
} 


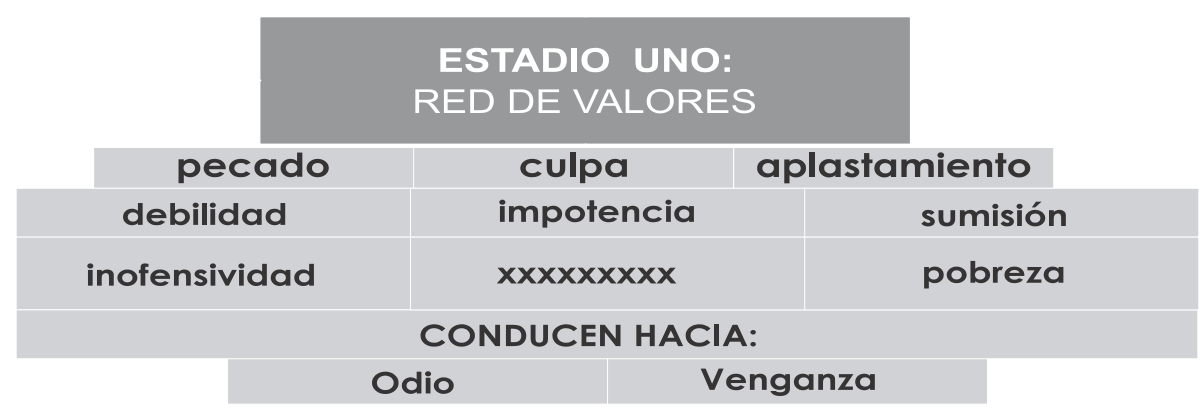

Figura 1.1 Estadio involutivo básico de la red de valores católicos

\section{Del autodesprecio al guerrerismo}

El papel degradante del autodesprecio exige flagelaciones y dolores que conducen a "[... una] condición enfermiza [que] ha crecido siempre en profundidad y extensión con una rapidez siniestra" (Nietzsche, 1994, p. 165). Inculcado desde la Colonia como herramienta de control social, el autodesprecio es una de las claves para entender el cuadro clínico de violencia social que hace metástasis sobre lo político (Zuleta, 2013 , pp. 84,85). No puede ser neutro que una sociedad entera se haya entrenado en aplicar sobre sus miembros terapias de tormentos, contriciones y espasmos de redención y que nada haya pasado dado que "[...] la neurosis religiosa aparece como una forma del < ser malvado> : de ello no hay duda." (Nietzsche, 1994, p. 165,166). Al indagar por el proceso de fabricación de estos valores, Nietzsche también denuncia que por debajo de todos ellos imperan el odio y la venganza develando el verdadero talante del Leviatán hobbesiano (Hobbes, 1987, pp. 370-385):

La venganza es fundante en la Iglesia. Se ha leído del hoy beato Juan Pablo II que "[...] toda violación de la dignidad personal [...] clama venganza delante de Dios [...]" (Juan Pablo II, 1988: 89). Estas exhortaciones generadas por autoridades eclesiales impulsan a sus creyentes hacia acciones justificadas por la venganza. En Colombia los análisis efectuados por la Comisión de Estudios sobre la Violencia (1988) y por Guzmán, Fals y Umaña (2005) constituyen muestra fehaciente de esta hipótesis, fijando entre las Ilamadas causas inmediatas de la violencia que sus víctimas "[...] almacenaron el combustible de odio y recelo [...] que más tarde [afloraría] para tomar venganza [...] el odio nos invadió [... en] tiempos en que se reunían colombianos [...] a cotizarse para comprar armas con las que pudieran defenderse o hacer asesinar a otros colombianos" (Guzmán, Fals \& Umaña, 2005 (2), p. 430). 


\section{ESTADIO DOS: \\ VALORES DE MUERTE

sacrificio Sanguinolencia Cadaveridad

Figura 1.2 Estadio involutivo de muerte

\section{Manifestaciones guerreras de la catolicidad}

Culto a la muerte, cadaveridad y violencia política

La catolicidad le rinde culto permanente a un sanguinolento anuncio de cadáver. El crucifijo forma parte del imaginario personal y colectivo en Colombia ayudando a explicar la religión como factor atizador de la violencia política (Congote, 2011, 2004). Los hechos y la doctrina católica conservan al cadavérico coronado de espinas imperando en la imaginería y el rito sociales.

Luego del pacto de Constantino en el siglo IV, el catolicismo hizo que el creyente resultara un culpable eterno "[...] los sufrientes mismos [que] sólo por medio de [la] expiación [y el] sufrimiento personal pueden purgar su culpa [...]" (Fromm, 1990:78. Nietzsche, 1994: 146,147. Freud, 1966). En ello descansa el surgimiento del paradigma católico de la violencia como expresión ritual, obedeciendo al cual: "El guerrero cristiano [... ] no le tiene miedo a la muerte: la desea [...] Los guerreros de Cristo dan seguros las batallas de su Señor, sin tener que temer el ofender a Dios al matar a un enemigo o peligro para sí mismos si mueren. En efecto, la muerte por Cristo [...] no es ningún crimen, y merece la más grande gloria [...] $\mathrm{Si}$ muere es por su bien, si mata es por el de Cristo" (De Roux 2003, p. 4). 
Tabla 2.1 Culto a la muerte y política en Colombia

\begin{tabular}{|c|c|c|}
\hline Página & Fenómeno & Observaciones \\
\hline $\begin{array}{c}\text { Perea, } \\
1996, \\
\text { p. } 27\end{array}$ & $\begin{array}{l}\text { "[...] en el centro de este atisbo sobre } \\
\text { los modos de construcción del poder [...] } \\
\text { partidario, está latente la pregunta por } \\
\text { una práctica de la muerte que se ha } \\
\text { instalado hasta en el último recoveco de } \\
\text { la vida pública y privada [...] la } \\
\text { violencia [...] se despliega, imperial, sin } \\
\text { que pueda ser incorporada en algún } \\
\text { circuito de la cultura capaz de } \\
\text { exorcisarle." }\end{array}$ & $\begin{array}{l}\text { Este circuito bien puede ser el } \\
\text { religioso, aunque no para } \\
\text { exorcisarlo sino para identificarlo } \\
\text { y generar responsabilidades } \\
\text { políticas. } \\
\end{array}$ \\
\hline $\begin{array}{l}\text { Perea, } \\
1996, \\
\text { p.118 }\end{array}$ & $\begin{array}{l}\text { "Si para capturar el mando hay que } \\
\text { exponer [...] mil vidas, el [...] político } \\
\text { debe exponerlas [...] Los muertos caen } \\
\text { para facilitarnos la faena y nuestra } \\
\text { misión como hombres políticos no es } \\
\text { vengar a los muertos sino llevar al poder } \\
\text { a los vivos." }\end{array}$ & $\begin{array}{l}\text { Este concepto enlaza los valores } \\
\text { de muerte: sacrificio, sanguino- } \\
\text { lencia y cadaveridad como } \\
\text { elementos de la máquina política } \\
\text { catolizada colombiana. }\end{array}$ \\
\hline $\begin{array}{l}\text { Perea, } \\
1996, \\
\text { p.121 }\end{array}$ & $\begin{array}{l}\text { "El liberalismo sólo conoce un medio de } \\
\text { hacer política: asesinar conservadores." }\end{array}$ & $\begin{array}{l}\text { Editorial del Diario El Siglo, Dic } \\
31 \text { 1946. En ese año se eligió a } \\
\text { Ospina Pérez presidente luego de } \\
\text { una aguda división liberal. El } \\
\text { asesinato, se enarbola entonces } \\
\text { como grito político y no } \\
\text { gratuitamente vendrá luego el de } \\
\text { Gaitán. "La repetición incansable } \\
\text { de la sorda imprecación [de } \\
\text { muerte] se ve revestida [...] de } \\
\text { motes que señalan la } \\
\text { administración de la muerte como } \\
\text { una inequívoca obra de barbarie } \\
\text { del adversario [...] en el contexto } \\
\text { de [esa] administración [...] que } \\
\text { ya no tiene obstáculos, el vínculo } \\
\text { entre violencia y democracia } \\
\text { termina por arrastrar con el } \\
\text { fundamento [... del] orden } \\
\text { político" (Perea, pp. 125-127. } \\
\text { Congote, 2006). }\end{array}$ \\
\hline
\end{tabular}




\begin{tabular}{|c|c|c|}
\hline Página & Fenómeno & Observaciones \\
\hline $\begin{array}{l}\text { Broderick, } \\
\text { 2000, } \\
\text { p. } 72\end{array}$ & $\begin{array}{l}\text { "[Para Vásquez lo fundamental era la } \\
\text { conmemoración de las gestas gloriosas } \\
\text { del ayer...] en una parodia inconsciente } \\
\text { de la liturgia cristiana que celebra, año } \\
\text { tras año en perpetua repetición, las } \\
\text { fiestas de los mártires y la muerte y } \\
\text { resurrección de su fundador." }\end{array}$ & $\begin{array}{l}\text { Este patrón comportamental surge } \\
\text { medular en la historia primera, } \\
\text { cristianizada, del ELN. }\end{array}$ \\
\hline $\begin{array}{l}\text { Broderick, } \\
2000 \\
\text { p. } 120\end{array}$ & $\begin{array}{l}\text { "[...] el velorio era el rito más } \\
\text { importante [de la estadía en Cartagena]. } \\
\text { Ese era el momento para explicarle a la } \\
\text { gente sus problemas [...] la necesidad } \\
\text { de organizarse. Si explicábamos eso en } \\
\text { la iglesia, nada. ¡Pero con el muerto } \\
\text { delante [...] Avemaría! ¡Para nosotros } \\
\text { ir al velorio era lo primero!" }\end{array}$ & $\begin{array}{l}\text { Relato de los primeros años del } \\
\text { cura Pérez, fundador del ELN en } \\
\text { Colombia. }\end{array}$ \\
\hline
\end{tabular}

Fuente: (Perea, 1996. Broderick, 2000. Negrillas del artículo)

Este estado de cosas tipificó desde la Colonia la operatividad de unos "sistemas integradores claves", que permiten entender cómo el comportamiento del colectivo indígena y mestizo criollo de los siglos XVI al XVIII estuvo marcado por la expresión de virtudes de sometimiento y violencia filosófica y teológicamente justificadas que se mantienen activas en el período republicano (Guillén, 1996, p. 47-238. Uribe, 2009. Zuleta, 2013) .

$3 \quad$ No es correcto asimilar el fenómeno violento atroz solo a los episodios bipartidistas de la segunda mitad del siglo XX. Tal como puede leerse, por ejemplo, en Pearce (1992): "[...] la mayoría [de los guerreros de la confrontación de 1885] no luchaba a favor de uno u otro partido por convicción sino porque tenía que vengar alguna atrocidad." 
"Durante el pasado siglo (XIX) y hasta nuestros días... (se) produjeron muchos más muertos como consecuencia de la polarización de la población y la exacerbación de sentimientos hostiles de unos contra otros, como si los mecanismos que controlan la agresividad... se hubieran debilitado al punto de no poderla contener de un desenlace violento individual y colectivo."

(Comisión, 1988, p. 294)

Tabla 2.2 Violencia política y valores católicos balance de 1988

\begin{tabular}{|c|c|c|}
\hline FENÓMENO VIOLENTO POLÍTICO & $\begin{array}{l}\text { VALORES } \\
\text { CATOLICOS } \\
\text { IMPLICADOS } \\
\text { JUSTIFICADOS } \\
\text { ONTOTEOLÓGI- } \\
\text { CAMENTE }^{5}\end{array}$ & $\begin{array}{c}\text { VALORES } \\
\text { CATÓLICOS } \\
\text { IMPLICADOS } \\
\text { JUSTIFICADOS } \\
\text { SOTERIOLÓGI- } \\
\text { CAMENTE6 }^{6}\end{array}$ \\
\hline $\begin{array}{l}\text { "[...] el propósito [...] de este informe [es] estudiar la } \\
\text { violencia [...] en la cual la eliminación física, o al } \\
\text { menos la lesión, es la consecuencia de acciones con } \\
\text { un componente fundamental de intencionalidad." } \\
\text { (Comisión, 1988: } 58 \text { ). }\end{array}$ & $\begin{array}{l}\text { Sacrificio, Derramamiento } \\
\text { de sangre, Exaltación de } \\
\text { cadaveridad, Odio y } \\
\text { venganza }\end{array}$ & \\
\hline $\begin{array}{l}\text { "[...] entre los delitos más frecuentes [...] se incluyeron } \\
\text { [...] prácticas que tienen por objeto la forma más directa } \\
\text { de agresión personal, y que reflejan una fuerte } \\
\text { tendencia a la agresividad y a la violencia." } \\
\text { (Comisión, 1988: } 65 \text { ). }\end{array}$ & $\begin{array}{l}\text { Sacrificio, Derramamiento } \\
\text { de sangre, Exaltación de } \\
\text { cadaveridad, Odio y } \\
\text { venganza }\end{array}$ & \\
\hline $\begin{array}{l}\text { "[La función principal de la justicia privada] consiste } \\
\text { en el amedrentamiento y la eliminación de ciudadanos } \\
\text { por (múltiples) razones [...]" (Comisión, 1988: 67,68) }\end{array}$ & $\begin{array}{l}\text { Sacrificio, Derramamiento } \\
\text { de sangre, Exaltación de } \\
\text { cadaveridad, Odio y } \\
\text { venganza }\end{array}$ & \\
\hline $\begin{array}{l}\text { "[El que diversas entidades conozcan] de un elevado } \\
\text { número de asesinatos y desapariciones de activistas } \\
\text { políticos, es [...] preocupante." (Comisión, 1988: 69). }\end{array}$ & $\begin{array}{l}\text { Sacrificio, Derramamiento } \\
\text { de sangre, Exaltación de } \\
\text { cadaveridad, Odio y } \\
\text { venganza }\end{array}$ & \\
\hline $\begin{array}{l}\text { "[Los escuadrones de la muerte] han rebasado [...] } \\
\text { sus objetivos [...] de [...] venganza, represalia e } \\
\text { intimidación [...]" (Comisión, 1988:93). }\end{array}$ & $\begin{array}{l}\text { Sacrificio, Derramamiento } \\
\text { de sangre, Exaltación de } \\
\text { cadaveridad, Odio y } \\
\text { venganza }\end{array}$ & $\begin{array}{l}\text { Autodesprecio, } \\
\text { Pecado, Culpa } \\
\text { Odio, Venganza }\end{array}$ \\
\hline
\end{tabular}

$4 \quad$ La Comisión acierta parcialmente en el diagnóstico. Esos valores que, en la generalidad de las sociedades, contribuyen a evitar desenlaces violentos en lo individual y colectivo, los hemos mostrado aquí imbricados en la propulsión de la violencia.

5 JUSTIFICACION ONTOTEOLÓGICA: Comportamientos humanos que se justifican por haber sido el dios cristiano el creador de todo y de todos.

6 JUSTIFICACION SOTERIOLÓGICA: Comportamientos humanos justificados porque solo el plan de vida ascético-místico del hombre puede darle la posibilidad de redención en el seno del ritual apocalíptico. 


\begin{tabular}{|c|c|c|}
\hline FENÓMENO VIOLENTO POLÍTICO & $\begin{array}{l}\text { VALORES } \\
\text { CATOLICOS } \\
\text { IMPLICADOS } \\
\text { JUSTIFICADOS } \\
\text { ONTOTEOLÓGI- } \\
\text { CAMENTE }\end{array}$ & $\begin{array}{c}\text { VALORES } \\
\text { CATÓLICOS } \\
\text { IMPLICADOS } \\
\text { JUSTIFICADOS } \\
\text { SOTERIOLÓGI- } \\
\text { CAMENTE }\end{array}$ \\
\hline $\begin{array}{l}\text { "La legislación general de la República no regirá entre } \\
\text { los salvajes [...] el Gobierno, de acuerdo con la } \\
\text { autoridad eclesiástica, determinará la manera como } \\
\text { esas incipientes sociedades [sic] deben ser gobernadas." } \\
(\text { Comisión, 1988: 107)7. }\end{array}$ & Sacrificio & $\begin{array}{l}\text { Autodesprecio, } \\
\text { Pecado, Culpa } \\
\text { Odio, Venganza }\end{array}$ \\
\hline $\begin{array}{l}\text { "[...] del lado rebelde, los sectores armados [...] sólo } \\
\text { conciben la victoria [...] como la derrota y destrucción } \\
\text { del enemigo o la propia muerte; desde el lado no } \\
\text { rebelde, [también creen lo mismo] los sectores que } \\
\text { [...] mediante bandas armadas [...] provocan la muerte } \\
\text { de aquellos con quienes [se podría negociar] un fin a } \\
\text { las hostilidades." (Comisión, 1988: } 295 \text {. Congote, } \\
2004 \text {, Capítulo 3)/8. }\end{array}$ & $\begin{array}{l}\text { Sacrificio, Derramamiento } \\
\text { de sangre, Exaltación de } \\
\text { cadaveridad, Odio y } \\
\text { venganza }\end{array}$ & \\
\hline
\end{tabular}

Fuente: (negrillas y notas entre corchetes, del artículo)

El discurso dogmático católico se ha constituido en uno de los ejes del conflicto colombiano contribuyendo "[...] a la ferocidad y al sectarismo de nuestra vida política [...]" (González 1997: 347-393). Soportes investigativos como el de la Comisión Justicia y Paz de la propia Iglesia Católica [actuaciones de 1986 y 1988] o las reflexiones sobre la 'pastoral para la paz' de la Conferencia Episcopal (1994), ratifican desde las propias plumas eclesiales ${ }^{9}$ "[...] que la opción armada [...] se inserta siempre dentro de inercias culturales, caracterizadas como una 'cultura de la violencia'[...] la Conferencia Episcopal de 1994 propone que los colombianos no[...] hacemos violencia coyuntural o esporádica, sino que somos una sociedad violenta". (Confepiscopal, 1994: 359, 361. Negrilla del artículo).

$7 \quad$ Está basada en el artículo 1 de la Ley 89 de 1890 de legislación indígena. González confirma que estas limitaciones informales trascendieron en el tiempo, dado que desde la Conquista existen pruebas fehacientes de que estos contravalores vinieron engarzados con el doctrinarismo eclesial conquistador. (González, 1997, pp. 42-56).

8 Téngase en cuenta este hecho como fundamento de las hipótesis centrales del artículo.

9 La Iglesia peca de ignorancia voluntaria en nuestra historia. Ver significado en Uribe (2009). 


\section{ESTADIO TRES: \\ MECANISMOS DE INOCULACIÓN \\ DE LA RED DE VALORES}

\begin{tabular}{|c|c|c|}
\hline Filosóficos & $\begin{array}{c}\text { - Lo moral se hace equivalente } \\
\text { a lo moral católico. } \\
\text { - Inoculan el autoritarismo. } \\
\text { - Inoculan la violencia como valor } \\
\text { justificado moralmente. }\end{array}$ \\
Políticos & $\begin{array}{c}\text { Inoculación de valores } \\
\text { mediante imposición del } \\
\text { aparato español } \\
\text { colonial violento - catolizado }\end{array}$
\end{tabular}

Figura 2.1 Estadio involutivo de inoculación de valores

\section{La máquina de guerra catolizada y el proceso de paz}

He buscado en los libros, en los paisajes, en las melodías y en las pasiones remedios para el mal del alma, ya que los que capciosamente ofrece el cristianismo son venenos melosos con los que los hombres mueren ignorantes de que el mal del alma es el mismísimo cristianismo"

(Cioran, 1998, p. 40).

\section{Patrones católicos inscritos en el discurso negociador}

El proceso inoculador-activador de los valores católicos ha tenido un disfraz religioso que oculta su operacionalidad política. Por ello conviene desnudarlos para enriquecer el diagnóstico del proceso negociador de la guerra civil en La Habana porque tanto los negociadores como las partes en conflicto y la mayoría social se ufanan de rendirle culto a esos valores. El artículo sugiere que este hecho ayudaría a explicar, no solo los sucesivos fracasos de procesos anteriores sino por qué la sostenibilidad del actual, también se encuentra en riesgo.

El artículo involucra a la Iglesia a este diagnóstico porque ella se estableció aquí como "[...] la representación de un programa cultural de experimentación universal [confirmando] su rol creador [léase inoculador] y reproductor [léase activador] social de los valores universales en ella cohesionados y por ella representados" (Zuleta, 2013, pp. 35, 97). De la mano de este mecano dogmático se podría entender la vigencia de algunos patrones que se han observado activos en el discurso que surge de la mesa en La Habana o desde diversos estamentos socio políticos en Colombia. 
Patrón 1. Colombia se ha construido y debe seguir operando como un sistema armónico de violencia. (Zuleta, 2013, pp. 39, 42).

Patrón 2. Colombia se ha edificado y debe seguir operando como un sistema de violencia autoritaria (Zuleta, 2013, pp. 42-63. Congote, 2011, Capítulo 3 . Congote, 2011, 2006, 2004).

Patrón 3. Colombia se ha construido y debe seguir operando como un sistema armónico de dominación. VIOLENCIA + AUTORITARISMO + DOMINACIÓN + POBREZA $<=>$ EJES DEL PRESENTE Y PORVENIR SOCIO-CULTURAL COLOMBIANO ${ }^{10}$. (Guillén, 1996, p.185).

Patrón 4. Colombia se ha construido y debe seguir operando como un sistema armónico de sumisión. ${ }^{11 / 12}$.

Patrón 5. Colombia se ha construido y debe seguir operando como un sistema armónico de empobrecimiento masivo y, al tiempo, protector de privilegios elitistas. (Gobierno Farc, 2014:6-13. Congote, 2014. Puiggros, 1989) ${ }^{13}$.

\section{Estudio del caso (2012-2014)}

\section{Fundamentos teóricos}

La pregunta: "¿En qué condiciones llegará a surgir la cooperación en un mundo de egoístas no sometidos a una autoridad central?" devela la prevalencia de cierto tipo de utopía en los teóricos de juegos (Axelrod, 1984, p. 15). Se pretende sugerir entonces que la cooperación sólo se desarrolle en sociedades regidas por autoridades centrales impuestas $\mathrm{y}$, por tanto, violentas [léase para Colombia: inspiradas en valores religiosos depredador-guerreristas]. El artículo propone, al contrario, que ese tipo de sociedades son las que ofrecen menores posibilidades para la cooperación social y que la construcción de sociedades horizontales humanistas podría permitir el diseño de juegos Gana-Gana.

10 La negociación agraria en La Habana (Punto 1) confirma este paradigma (Gobierno Farc, 2014. Congote, 2014)

11 "[...] en la mayoría de las zonas del país la sociedad sacralizada, quiere insistir en la importancia de la vida celestial, tesis que lateralmente sirve para mantener al pueblo resignado ante sus sufrimientos [...] y subyugado políticamente [...] esta [...] aceptación del sufrimiento como cosa que dios recompensaría especialmente explica en parte la tradicional resignación religiosa y política de los grupos sociales [...]" (Fals, 1985, p. 35).

12 El documento de las negociaciones políticas confirma la existencia en la mesa de La Habana de una clara relación autoritarismo - sumisión (Gobierno-Farc, 2014, 14-26).

13 Fenómeno materializado políticamente en un sistema armónico de clientelismo escriturado a nombre de barones electorales que prostituyen el derecho al voto a cambio de micro favores para minorías cooptadas (Arias, 2010). 
Un ejercicio a manera de balance permitiría identificar estos elementos del juego negociador:

a. La existencia de jugadores: Negociadores desarmados: Ciudadanos gobernantes; Ciudadanos políticos; Ciudadanos agremiados. No negociadores: Ciudadanos gobernantes, políticos, militares, agremiados, armados. Refrendadores de acuerdos: Población civil votante.

b. La existencia de decisiones de juego: Dilatar - acelerar las negociaciones; Preservar - romper el status quo si se quiere dejar-conservar las armas (Gobierno -Farc, 2014, p.15); Obstruir - facilitar el desarme (Gobierno-Farc, 2014, p. 15); Obstruir - facilitar la negociación.

c. La existencia de posibles pagos o remuneraciones a dichas decisiones: Negociadores estatales: procuran mantener privilegios; conservar control político; reelegirse socavando reglas democráticas; mantener la exclusión política, económica; mantener paradigmas de dominación depredador-excluyentes, infiltrar al contrincante negociador; hacerle guerra sucia. Negociadores insurgentes: procuran mantener privilegios sin incorporarse a la vida civil; temen exponer sus vidas ante negociaciones no sostenibles; pretenden eludir el escrutinio electoral vía Asamblea Constituyente; mantienen mecanismos de sumisión manipuladora del tipo depredador-excluyente.

d. La existencia de un Estado de guerra reconocido por ambos jugadores: La guerra como suma de empresas, intereses y beneficiarios (el negocio legal e ilegal de las armas y utensilios complementarios; el tráfico de estupefacientes; la extorsión; la usurpación privada de porcentajes importantes de los contratos públicos). La guerra como atractivo tributario (la imposición permanente de impuestos extraordinarios de "sacrificio por la patria"; la imposición de micro leyes tributarias en zonas de guerra para beneficio de facciones armadas). La guerra como espacio propicio para la especulación económica (conservar el acaparamiento y el contrabando en manos de los administradores de la guerra obstaculizando el libre comercio, bloqueando la competencia, la libre entrada y el flujo simétrico de información en el mercado de bienes y servicios). La guerra como factor mafioso de extorsión-amenaza política (elegir a los que nos "protegen" del terrorismo versus elegir a quienes nos lanzarán al optimismo creativo; candidatizar a los que ofrecen soluciones facilistas y rápidas en La Habana (Ramírez, 2014).

Este balance sugiere que en tanto se continúe negociando sin develar esta agenda oculta depredador-guerrerista, en La Habana se consolide un juego del tipo Dilema del Prisionero que admita un "faltoneo" razonable entre las partes hacia soluciones no sostenibles o, peor, sosteniendo un juego cuyo fin sea terminar las negociaciones. 
Un juego de este tipo está basado en el falaz supuesto de que el político es un juego de suma cero del tipo: la paz se logra una sola vez con la firma de un solo acuerdo que contenga la mayor cantidad de trampas [léase: permisos de hacer trampa].

\section{Análisis del juego actual}

La actual negociación pacificadora se perfila como un juego del tipo Dilema del Prisionero con solución hacer trampa recíprocamente. El actual juego negociador tiende a resolverse no cooperativamente dado que en este tipo de juego "[...] la defección proporciona siempre un resultado mejor que la cooperación" (Axelrod, 1984 , p. 19). Sin embargo especulamos que a ambos jugadores armados [Estado e Insurgencia] y al jugador central [la masa crítica social] les convenga cooperar para garantizar que el juego social continúe exitosamente una vez firmados los acuerdos dado que "[...] existen una variedad de mecanismos que emplean las partes de un acuerdo [faltón] para disminuir sus costos de transacción; encontrarse repetidamente; fortalecer sus acuerdos y blindarse contra [el fracaso, una de cuyas herramientas, paradójicamente consiste] en presentar un trato [faltón como si fuera] una relación sólidamente establecida (Lambsdorff et al., 2002, p. 11. Notas entre corchetes del artículo).

La siguiente sería la estructura del juego negociador actual:

REGLAS. Tipo del Juego: Dilema del prisionero. Patrones del juego: DepredadorGuerreristas. Flujo de información: Asimétrica producto de negociaciones relativamente secretas. Solución: Alto riesgo de trampa.

JUGADORES: Negociador estatal armado (nea); Negociador insurgente armado (nia); Sociedad civil refrendadora [scr) ${ }^{14}$

PAGOS DEL JUEGO ${ }^{15}$ : Pago que recibiría el nea por cooperar con el nia = Desarme (d). Pago que recibiría el nia por cooperar con el nea $=$ Inserción democrática (id). Pago que recibiría el nea por no cooperar $=$ Cero (0). Pago que recibiría el nia por no cooperar $=$ Cero (0). Pagos que recibirían el nea y el nia por hacer trampa $=$ (desarme (d) e Inserción Democrática (id) no sostenibles)

\footnotetext{
14 Habiéndose aprobado un mecanismo plebiscitario.

15 El artículo tiene claro que en el actual proceso los pagos son más complejos porque estarían repartidos entre cada uno de los que parecen ser cuatro (4) puntos pre agendados. Ello no obsta para que el modelo aplicado resulte explicativo robusto porque, a pesar de la tipificación del juego como uno Dilema del Prisionero estaría operando una regla de un juego tipo Seguro según la cual "nada está acordado hasta que todo esté acordado" (Gobierno-Farc, 2014, pp. 5,13).
} 
Tabla 4.1 Pagos del juego actual tipo Dilema del Prisionero

\begin{tabular}{|c|c|c|}
\hline $\begin{array}{c}\text { Pagos del juego actual } \\
\text { tipo Dilema del } \\
\text { PrisioneroXxxxxxxxxxx }\end{array}$ & $\begin{array}{c}\text { Negociador insurgente } \\
\text { armado }\end{array}$ & Nia \\
\hline $\begin{array}{c}\text { Negociador estatal } \\
\text { armado }\end{array}$ & No Coopera, No coopera & No Coopera, Coopera \\
\cline { 2 - 3 } & (Paga "0", Paga "0") & (No paga "id", Paga "d") \\
\hline \multirow{2}{*}{ Nea } & Coopera, No coopera & Hace trampa, Hace trampa \\
\cline { 2 - 3 } & (Paga "id", No paga "d") & (Pagos "d" e "id" insostenibles) \\
\hline
\end{tabular}

Tabla 4.2 Soluciones negociadoras del Dilema del Prisionero

\begin{tabular}{|c|c|c|}
\hline \multirow{2}{*}{ xxxxxxxxxxxx} & $\begin{array}{c}\text { Negociador insurgente } \\
\text { armado }\end{array}$ & Nia \\
\hline \multirow{3}{*}{$\begin{array}{c}\text { Negociador estatal } \\
\text { armado }\end{array}$} & No Coopera, No coopera & No Coopera, Coopera \\
\cline { 2 - 3 } & (Paga "0", Paga "0") & (No paga "id", Paga "d") \\
\cline { 2 - 3 } & GUERRA PERMANENTE & AMENAZA DE \\
& & SEGUIR LA GUERRA \\
\hline \multirow{3}{*}{ Nea } & Coopera, No coopera & Hace trampa, Hace trampa \\
\cline { 2 - 3 } & Paga "id", No paga "d" & (Pagos "d" e "id" insostenibles) \\
\cline { 2 - 3 } & AMENAZA DE & CONTINUACIÓN \\
& SEGUIR LA GUERRA & DE LA GUERRA \\
\hline
\end{tabular}

La estrategia dominante del juego tipificado como Dilema del Prisionero, es una de faltoneo recíproco del tipo Pierde-Pierde, materializada en que: El jugador nea expresa su estrategia no cooperativa con el jugador nia no ofreciéndole el pago Inserción Democrática (id) o, si se lo ofrece firmando un acuerdo, no comprometiéndose a sostenerlo. El jugador nia expresaría su estrategia no cooperativa con el jugador nea no ofreciéndole el pago Desarme (d) o, si se lo ofrece firmando un acuerdo, no comprometiéndose a sostenerlo. $Y$ en que, el jugador scr no cooperaría con los jugadores nea y nia porque la asimetría de la información y un acuerdo faltón le induciría sea a votar con dudas sea abstenerse de votar por acuerdos cuya sostenibilidad sea dudosa.

\section{Propuesta de una [¿utópica?] opción de juego cooperativo ${ }^{16 / 17}$}

La solución que propone el artículo está basada en el recurso de la demostración por el absurdo en relación con que resulta utópico que una sociedad anclada en

16 El autor del artículo participó en el diseño, monitoreo y evaluación de un exitoso experimento social en la Costa Atlántica de Colombia, con base en este tipo de juego (Congote, 2003a).

17 Cumpliendo las condiciones clásicas de la cooperación, esto es: repetición del juego, información completa en manos de los jugadores y un número relativamente pequeño de jugadores (Elster, 1989). Sin embargo, especulamos sobre la tesis de North en el sentido de que en ausencia de alguna de estas reglas, ellas puedan ser dinamizadas [¿garantizadas?] mediante coacción 
valores católicos pueda negociar sostenible y cooperativamente. Sin embargo, puede ser que un juego cooperativo permita reconstruir el juego actual sobre la base de que la política se juega bajo subtipos iterativos de suma infinita, no bajo subtipos de suma cero como es propio jugar con base en una red de valores catolizada.

Adicionalmente, en política es saludable negociar cooperativamente porque los negociadores reconocerían que una vez terminadas las negociaciones estarán forzados a interactuar continuamente en el ejercicio de cada uno de sus roles sociopolíticos ${ }^{18}$. Lo anterior se sustenta, además, en el hecho democrático participativo de que, una vez suscrito el acuerdo negociado, éste será sometido al escrutinio ciudadano ${ }^{19}$.

La Teoría de Juegos sugiere que Colombia podría rediseñar las reglas del juego negociador actual hacia uno cooperativo donde el "faltoneo" no sea admisible. Pero, cuando los valores de los jugadores operan bajo una agenda religiosa oculta del tipo depredador-guerrerista no cuestionada, como ocurre ahora, el juego tiende a mantenerse como uno del tipo Dilema del Prisionero, inclusive si se pactarajugar cooperativamente, haciendo fracasar sus acuerdos.

Pero podría ocurrir que el juego cooperativo se viera fortalecido por una variación sutil de la misma agenda depredador-guerrista: la < cultura mafiosa > que ha inspirado buena parte del ejercicio político en Colombia (Garay 2002, 2000, 1999). En efecto, continuar jugando al "faltoneo" obedecería a la concepción mafiosa de la guerra. "Lo que propongo es una medida extrema [...] Pero hay veces en que cualquier extremismo está justificado [...] había demasiadas facciones, demasiados intereses opuestos. El acuerdo era imposible." (Puzo, 1970, p. 138, 224). Esto supondría que el "faltoneo" no fuera un riesgo marginal, como se cree, porque les podría significar a los jugadores construir una salida hacia un agujero negro: el exterminio recíproco ${ }^{20}$. Mafiosamente hablando, terminaríamos cooperando para no exterminarnos...

\section{La opción cooperativa}

La teoría de juegos le aporta a la negociación de paz colombiana la posibilidad de aceptar que jugadores que hoy juegan haciendo trampa pasen a cooperar. Jugar

institucional [papel que, en el caso del proceso de paz, le estaría asignado a determinados organismos de control internacionales tipo Naciones Unidas, Unión Europea, Organización de Estados Americanos o Corte Penal Internacional]. (North, 1993, Capítulos II, III).

18 A este respecto el artículo menciona que el proceso de paz en Sudáfrica duró seis años, plazo durante el cual fue reiniciado desde cero en varias oportunidades. (Meyer, 2013).

19 Ley Estatutaria de Referendo por la Paz aprobada por Cámara y Senado de Colombia el 5 de noviembre 2013 (a revisión de la Corte Constitucional), recientemente ajustada a una solución plebiscitaria (Congreso de Colombia, Cámara de Representantes, diciembre 4 2015).

20 Los contenidos conocidos en enero de los pre acuerdos sobre los puntos 1 y 2 , anuncian el riesgo de que un debate represado - secreto, como es el propuesto, haga crisis cuando llegue la hora de refrendarlo (Gobierno-Farc, 2014). 
Seguro, como es el tipo de juego propuesto, se recomienda porque tiene como estrategia dominante Cooperar - Cooperar. No sólo porque las partes poseen una percepción clara de sus pagos y la sostenibilidad del compromiso para recibirlos, sino porque los jugadores aceptarían niveles simétricos de información rompiendo el actual régimen secreto. Mucho más si se toma en cuenta que si los acuerdos van a quedar sometidos a refrendación popular la sociedad civil necesita información simétrica para decidir con transparencia. Una y otra cosa sin importar que el proceso deba prolongarse en el tiempo todo lo necesario, contrariando los discursos inmediatistas inspirados por las facciones depredador-guerreristas del establecimiento como la uribista o la conservadora ${ }^{21}$.

Con base en estos antecedentes se podría rediseñar el juego negociador hacia uno del tipo seguro cooperativo con información simétrica y sin límites temporales artificiales, así:

Reglas de juego.: Tipo: Juego del Seguro. Patrones: cooperativos. Información simétrica abierta. Mínimos riesgos de faltoneo

Jugadores: Negociador estatal armado (nea). Negociador insurgente armado (nia). Sociedad civil refrendadora (scr).

Pagos $^{22}$. Pago que recibiría el nea por cooperar con el nia $=$ Desarme (d). Pago que recibiría el nia por cooperar con el nea $=$ Inserción democrática (id). Pago que recibiría el nea por no cooperar $=$ Cero (0). Pago que recibiría el nia por no cooperar $=$ Cero (0). Pagos que recibirían el nea y el nia por cooperar $=[$ Desarme $(\mathbf{d})$ e Inserción democrática (id) sostenibles $]$

Tabla 4.3 Pagos que genera el Juego del Seguro

\begin{tabular}{|c|c|c|}
\hline xxxxxxxxxxx & $\begin{array}{c}\text { Negociador insurgente } \\
\text { armado }\end{array}$ & Nia \\
\hline $\begin{array}{c}\text { Negociador estatal } \\
\text { armado }\end{array}$ & No Coopera, No coopera & No Coopera, Coopera \\
\cline { 2 - 3 } Nea & (Paga "0", Paga "0") & (No paga "id", Paga "d") \\
\hline \multirow{2}{*}{ Coopera, No coopera } & Coopera, Coopera \\
\cline { 2 - 3 } & (Paga "id", No paga "d") & (Pagos "d"e "id" sostenibles) \\
\hline
\end{tabular}

21 El partido Centro Democrático votó negativamente la solución plebiscitaria en la sesión final del Congreso, Cámara, diciembre 42015.

22 Es claro que, en el actual proceso, los pagos están tipificados según cada uno de los cuatro puntos pre agendados. Ello no obsta para que el modelo utilizado resulte útil dado que, en medio de sus riesgos, se ha aceptado una regla del juego Seguro según la cual "hasta que todo esté aceptado, nada está aceptado". 
Tabla 4.4 Soluciones negociadoras del Juego del Seguro

\begin{tabular}{|c|c|c|}
\hline xxxxxxxxxxxx & $\begin{array}{c}\text { Negociador insurgente } \\
\text { armado }\end{array}$ & Nia \\
\hline $\begin{array}{c}\text { Negociador estatal } \\
\text { armado } \\
\text { Nea }\end{array}$ & No Coopera, No coopera & No Coopera, Coopera \\
\cline { 2 - 3 } & (Paga "0", Paga "0") & (No paga "id", Paga "d") \\
\cline { 2 - 3 } & GUERRA PERMANENTE & $\begin{array}{c}\text { AMENAZA DE } \\
\text { SEGUIR LA GUERRA }\end{array}$ \\
\hline \multirow{3}{*}{ Nea } & Coopera, No coopera & Coopera, Coopera \\
\cline { 2 - 3 } & Paga "id", No paga "d" & (Pagos "d" e "id" sostenibles) \\
\cline { 2 - 3 } & $\begin{array}{c}\text { AMENAZA DE } \\
\text { SEGUIR LA GUERRA }\end{array}$ & PAZ SOSTENIBLE \\
\hline
\end{tabular}

La estrategia dominante del juego Seguro sería, por tanto Gana-Gana, materializada en que: El jugador nea expresaría su estrategia cooperativa con el jugador nia ofreciéndole como pago la Inserción Democrática (id) y comprometiéndose a sostenerlo mediante acuerdo. El jugador nia expresaría su estrategia cooperativa con el jugador nea ofreciéndole como pago el Desarme (d) y comprometiéndose a sostenerlo mediante acuerdo. $Y$ en que el jugador scr expresaría su estrategia cooperativa refrendando acuerdos acerca de los cuales ha estado informado simétricamente (sin secretos).

\section{Conclusiones}

"[...] una guerra de exterminio, en la que puede producirse la desaparición de ambas partes [...], sólo posibilitaría la paz perpetua sobre el gran cementerio de la especie humana y por consiguiente no puede permitirse ni una guerra semejante ni el uso de los medios conducentes a ella."

(Kant, 2005, p.10)

Primera. Las soluciones cooperativas producto del juego seguro no enfrentan obstáculos superficiales. Al contrario, se encuentran con oposiciones estructuradas por parte de agentes que obran inspirados en una red de valores depredadoresguerreristas que, como los católicos, se ha mantenido activa en la sociedad colombiana con persistentes y multiformes manifestaciones violentas.

Segunda. Esa red de valores puede llevar al proceso de negociación a continuar como uno no cooperativo de suma cero del tipo Pierde-Pierde, sobre todo si sus defensores siguen argumentando que el "faltoneo" sea admisible sin sanción alguna ${ }^{23}$.

23 $\quad$ Advirtiendo que "Los gobiernos tienen que disuadir a los ciudadanos para que no infrinjan las leyes [...] El propósito del gobierno es mantener la reputación de que es capaz de descubrir y procesar a los infractores, buscando así disuadir [...]" (Axelrod, 1984, pp. 147,148). El problema descansaría en buscar solución al obstáculo de que sea la red de valores culturales imperante la que tienda a socavar esta fundamental misión gubernamental de modo que inclusive las sanciones terminen por no afectar la reputación del sancionado [o sancionable] y, para peor, horadar la del sancionador (debido al clima de impunidad reinante). 
Tercera. Debido a sus valores depredadores - guerreristas, Colombia arriesga que el "faltoneo" negociador solo produzca efectos menores Ilevando a la insostenibilidad de todo acuerdo negociador después de firmado.

Cuarta. Para avanzar hacia una negociación pacifista sostenible sería fundamental rediseñar el juego actual y poner sobre la mesa primero, lo tóxico de los valores depredador-guerrreristas imperantes, segundo, las diferencias y beneficios que trae consigo un juego Coopera-Coopera y, tercero, aceptando que el juego del "faltoneo" puede conducir al exterminio de todos los jugadores.

Quinta. En la concepción teórica básica de la teoría de juegos, el de la negociación simétrica del tipo < Seguro > es uno de solución Gana - Gana cooperativa y sostenible dado que en él ambos jugadores tienden a cooperar porque lo aceptan como objetivo único, exc/uyente y permanente.

\section{Referencias}

Axelrod, R. (1984). La evolución de la cooperación. El dilema del prisionero y la teoría de juegos. Madrid: Alianza.

Bataille, G. (1981). Teoría de la religión. Madrid: Taurus.

Broderick, W. (2000). El guerrillero invisible. Bogotá: Intermedio.

Cioran, E. (1998). Breviario de los vencidos. Barcelona: Tusquets.

Congote, B. (2011). La Iglesia (agazapada) en la violencia política. Charleston (USA). Recuperado de www.amazon.com

De Loyola, I. (1947). Obras completas. Madrid: BAC, Tomo I.

Elster, J. (1989). Ulises y las sirenas. Estudios sobre racionalidad e irracionalidad. México: FCE.

Freud, S. (1966). Totem y tabú. Madrid: Alianza.

Fromm, E. (1990). El dogma de Cristo. Barcelona: Paidós.

Garay, L. (1999). Globalización y crisis. Bogotá: Tercer Mundo.

Garay, L. (2000). Ciudadanía, lo público, democracia. Textos y Notas. Bogotá: Litocencoa. 
Geertz, C. (1973). The interpretation of cultures. New York: Harper Torchbooks.

González, F. (1997). Poderes enfrentados. Iglesia y Estado en Colombia. Bogotá: Cinep.

Guillén, F. (1996). El poder político en Colombia. Bogotá: Planeta.

Guzmán, G., Fals, O. \& Umaña, E. (2005). La violencia en Colombia. Bogotá: Taurus.

Hayek, F. (1996). Los fundamentos de la libertad (I). Barcelona: Folio.

Hobbes, T. (1987). Leviatán o la materia, forma y poder de una república eclesiástica y civil. México: FCE.

Juan Pablo II. (1988). Los fieles laicos. Bogotá: San Pablo.

Kant, I. (2005). Sobre la paz perpetua. Madrid: Tecnos.

Nietzsche, F. (1994). Sobre la genealogía de la moral. Un escrito polémico. Madrid: Alianza.

North, D. (1993). Instituciones, cambio institucional y desempeño económico. México: FCE.

Pearce, J. (1992). Colombia dentro del laberinto. Bogotá: Altamir.

Perea, C. (1996). Porque la sangre es espíritu. Imaginario y discurso político de las élites capitalinas (1942-1949). Bogotá: IEPRI-Aguilar.

Puiggros, R. (1989). La España que conquistó el Nuevo Mundo. Bogotá: Áncora.

Puzo, M. (1970). El Padrino. Barcelona: Grijalbo.

Schwimmer, E. (1982). Religión y cultura. Barcelona: Anagrama.

Uribe, A. (2009). Perfiles del mal en la historia de Colombia. Bogotá: Universidad Nacional de Colombia.

Zuleta, B. (2013). Territorio y catolicismo en Colombia: Antioquia (siglos XVII$X X)$. Bogotá: Universidad Nacional de Colombia.

Arias, A. (2010). Descripción, análisis y evaluación del partido liberal en Pereira, Armenia y Manizales, periodo 1974-2006. Tesis inédita de Maestría de Ciencia Política, Universidad de los Andes, Bogotá. 
Barabas, A. (1991a). Editorial. En A. Barabas (comp.), El mesianismo contemporáneo en América Latina. México: Religiones Latinoamericanas.

Barabas, A. (1991b). Movimientos sociorreligiosos y ciencias sociales. En Alicia Barabas (comp.). El mesianismo contemporáneo en América Latina. México: Religiones Latinoamericanas.

Comisión de Estudios sobre la Violencia (1988). Colombia: violencia y democracia. Informe presentado al Ministerio de Gobierno. (2 ${ }^{a}$ ed.). Bogotá: UNColciencias.

Conferencia Episcopal Colombiana -Confepiscopal-. (1994). Hacia una pastoral para la paz. Secretariado Nacional de Pastoral Social.

Congote, B. (2006, sep.). La ética católica y el espíritu de la guerra en Colombia. Santander, España. En Ponencia XII Congreso Latinoamericanistas Españoles. Recuperado de htpp://www.halshs.archives-ouvertes.fr/REDIAL.

Congote, B. (2004). Anatomía religiosa de la guerra. Tesis de maestría de Ciencia Política. Universidad de los Andes, Bogotá.

Congote, B. $\left(2003^{\mathrm{a}}\right)$. ¿Se pueden construir relaciones cooperativas en el sector de Servicios Públicos? La teoría de juegos en el caso de Colombia. Recuperado de www.iadb.org/etica//sp4321/DocHit.cfm?Doclndex $=1365$.

Congreso de la República de Colombia. (2013, 5 de nov.). Ley Estatutaria de Referendo por la Paz aprobada por Cámara y Senado de Colombia. Bogotá: Gaceta del Congreso.

De Roux, R. (2003, agosto). Santas y justas lides. La guerra y el Dios cristiano en suelo americano. Barranquilla: Universidad del Norte. Ponencia.

Fals, O. (1985). Lo sacro y lo violento, aspectos problemáticos del desarrollo de Colombia. Revista Nueva Prensa, 135, 79-88.

Ferro, G. (1999). La geografía de lo sagrado: escenario para la batalla, la circulación y la apropiación de signos. El culto a la virgen de Las Lajas. Tesis de Maestría de Historia Andina, Universidad del Valle.

Garay, L. J. (2002,19 de mayo). Repensar a Colombia. Diario El Tiempo. Lecturas Dominicales.

Gobierno-Farc. (2014-01). Informe conjunto de la mesa de conversaciones entre el Gobierno de Colombia y las Fuerzas Armadas Revolucionarias de ColombiaEjército del Pueblo, FARC-EP. Diario El Espectador. Separata inserta. 
Lambsdorff, Graff et.al. (2002). Corrupt relational contracting. Recuperado de www.icgg.org/corruption.research_contributions

Meyer, R. (2013, 21 de oct.). Proceso de paz y fin del apartheid en Sudáfrica. Programa "Diálogos", de Canal Capital. Recuperado de www.canalcapital.gov.co

Ramírez, M. (2014, 28 de feb.). Ojalá que estemos unidos en esta campaña. Diario El Tiempo.

Ross, M. (1999). Culture and identity in comparative political analysis. En M. Lichbach \& A. Zuckerman (comp.). Comparative politics. Rationality, Culture, and Structure. NewYork: Cambridge. 